\title{
KAJIAN PENGGUNAAN PROGRAM APLIKASI DESAIN KAPAL TRADISIONAL PADA GALANGAN KAPAL KAYU DI KABUPATEN BATANG
}

\author{
Andi Trimulyono ${ }^{1)}$, Wilma Amiruddin ${ }^{1)}$, Eko Didik Purwanto ${ }^{2)}$, Bandi sasmito ${ }^{3)}$ \\ ${ }^{1)}$ Jurusan Teknik Perkapalan, Fakultas Teknik, Universitas Diponegoro \\ ${ }^{2)}$ Jurusan Sistem Komputer, Fakultas Teknik, Universitas Diponegoro \\ ${ }^{3)}$ Jurusan Teknik Geodesi, Fakultas Teknik, Universitas Diponegoro \\ Email: andi_trimulyono@undip.ac.id
}

\begin{abstract}
Abstrak
Kabupaten Batang terletak di pantai utara Jawa Tengah dimana wilayah pesisir kabupaten ini terdapat potensi yang dapat dikembangkan menjadi aset yang berharga bagi bangsa yaitu para pembuat kapal tradisional. Sebagian besar para pengrajin kapal kayu tradisional dalam pembangunan konstruksi kapal tanpa melalui proses rancang bangun secara modern. Dalam pelaksanaannya, baik tipe ataupun bentuk kapal yang dibangun, berdasarkan pengalaman kapal-kapal yang pernah dibuat sebelumnya dan tanpa melalui perhitungan dan penggambaran terlebih dahulu, sehingga dalam beberapa kasus terhadap pesanan kapal yang berbeda bentuknya, maka pengrajin ini akan mengalami kesulitan. (Wahyono,2011)

Hal ini menyebabkan perlunya sosialisasi mengenai teknologi perkapalan kepada pengrajin kapal di kabupaten Batang terutama dibidang rancang bangun(design) dan konstruksi kapal agar terdapat standar baku mengenai konstruksi kapal kayu yang sesuai dengan standar yang ada seperti Biro Klasifikasi Indonesia (BKI) sehingga kapal akan memenuhi tingkat standar yang baku dan tidak terjadi konstruksi yang berlebihan(over construction). Dengan melakukan sosialisasi dan workshop yang dilaksanakan di galangan kapal kayu menggunakan program aplikasi fishipro membuat pekerjaan lebih efisien serta penggunaan program aplikasi lainnya untuk memudahkan proses desain kapal kayu yang diproduksi oleh CV. Abadi Group yang terletak di Kabupaten Batang.
\end{abstract}

Kata kunci: Kapal Tradisional, Konstruksi kapal, Fishipro

\section{PENDAHULUAN \\ 1.1 Latar Belakang}

Kabupaten Batang terletakdi pantai utara Jawa Tengah dengan luas daerah $788,642 \mathrm{~km}^{2}$ diwilayah pesisir kabupaten ini terdapat potensi yang dapat dikembangkan sehingga dapat menjadi aset yang berharga bagi bangsa yaitu para pembuat kapal tradisional. Para pengrajin kapal kayu ini mampu menghasilkan kapal tipe mini purse seine yang mampu berlayar dalam radius pelayaran $12-$ 200 mile laut. Kabupaten Batang memiliki garis pantai yang cukup panjang, yaitu $38,73 \mathrm{~km}$ garis pantai tersebut terbentang dari Kecamatan Batang, Kecamatan Tulis, Kecamatan Subah, Kecamatan Limpung dan Kecamatan Gringsing dengan demikian sebagian besar penduduk di Kecamatan tersebut berada di jalur Pantai Utara, yang merupakan daerah pesisir yang bermata pencaharian di bidang perikanan laut seperti nelayan, pengelola ikan laut dll. (www.batang.go.id). berdasarkan dari hasil kajian KKN-PPM tematik Undip[2] terdapat beberapa hal yang masih perlu dikaji untuk meningkatkan kualitas dari desain kapal maupun konstruksi kapal kayu. Konstruksi kapal yang dibuat dengan ikatan yang sederhana untuk pembuatan gadinggading kapal ini terlihat pada Gambar 1. Dimana setiap sambungan menggunakan desain konstruksi yang sangat sederhana dikarenakan pengetahuan teknik yang dimiliki para pekerja dikalangan kapal kayu pun sederhana yang mana pekerjanya mayoritas lulusan SMP dan SMA. Dimana ilmu membuat kapal maupun konstruksi kapal didapatkan berdasarkan ilmu yang dipelajari 
secara turun temurn oleh para pekerja terdahulunya pada pekerja yang lebih muda. Dalam pelaksanaannya, baik tipe ataupun bentuk kapal yang dibangun, berdasarkan pengalaman kapal-kapal yang pernah dibuat sebelumnya dan tanpa melalui perhitungan dan penggambaran terlebih dahulu, sehingga dalam beberapa kasus terhadap pesanan kapal yang berbeda bentuknya, maka pengrajin ini akan mengalami kesulitan[8]. Mengingat perkembangan teknologi sudah sangatlah maju, maka diperlukan kecepatan dan ketepatan dalam proses pembuatan kapal perikanan khususnya kayu baik dalam segi desain maupun konstruksinya. Pembangunan kapal kayu untuk tujuan kegiatan usaha penangkapan ikan memerlukan teknik pengerjaan yang sesuai dengan prosedur dan persyaratan yang diatur berdasarkan ketentuan yang berlaku serta sesuai dengan standart yang telah ditetapkan dalam Biro Klasifikasi Indonesia(BKI)[8]

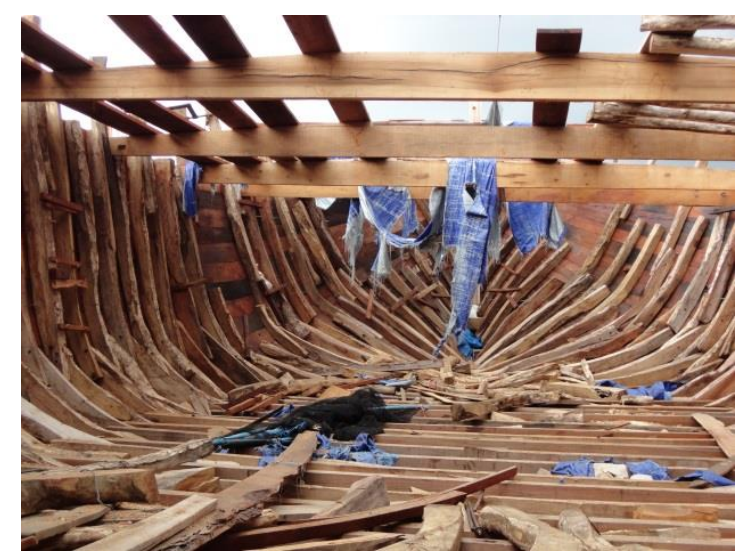

Gambar 1. Konstruksi kapal kayu yang dibuat pada galangan kapal kayu.

Berdasarkan hasil akhir penelitian inventarisasi Regristrasi Kapal Nelayan pantura Jawa tengah jumlah kapal nelayan yang beroperasi di sepanjang pantai utara Jawa Tengah kurang lebih 19.652 buah dari berbagai type dan ukuran. Dari jumlah tersebut di Sendang Sekucing terdapat 276 kapal dan perahu, yang terbagi sebagai berikut ; 70\% [6] terdiri dari perahu-perahu sopek yang mempunyai ukuran yang hampir sama dan menggunakan mesin tempel dari berbagai merk dan jumlah terbanyak adalah Dongfeng \& Kubota ini menunjukkan bahwa kabupaten Batang memiliki potensi untuk mengembangkan industri kapal kayu secara nasional
Kabupaten Batang merupakan salah satu kabupaten yang memiliki potensi untuk produksi kapal. Dilihat dari segi produktifitas galangan, terbukti CV. Laksana Abadi sebagai galangan kapal tradisional mampu memproduksi kapal berjumlah 18 unit dalam jangka waktu 12 bulan. Kapal-kapal yang dibangun di galangan Laksana Abadi memiliki variasi ukuran yang beraneka ragam, mulai dari kapal dengan ukuran lunas 10 meter, 15 meter, sampai ukuran lunas 25 meter. Produk kapal mereka memiliki beberapa keunggulan dibanding kapal tradisional lain , yaitu: stabilitas yang baik dan mesin utama berada di dalam (In board engine). Berdasarkan tingkat produktifitas CV. Laksana Abadi memiliki kapasitas yang cukup baik ini terlihat dari hasil kapal kayu yang dapat dibangun oleh CV. Laksana Abadi pada tahun 2011 ini dapat di lihat pada Tabel 1 dibawah ini

Tabel 1. Data Pembangunan Kapal Kayu Tahun 2011

\begin{tabular}{|l|c|}
\hline JENIS KAPAL & JUMLAH \\
\hline PURSE SEINE TEGAL 30 GT & 2 \\
\hline PURSE SEINE 30 GT & 8 \\
\hline JARING CUMI 30 GT & 4 \\
\hline $\begin{array}{l}\text { KAPAL IKAN PENAMPUNG } \\
\text { 46 GT }\end{array}$ & 3 \\
\hline $\begin{array}{l}\text { KAPAL IKAN PENAMPUNG } \\
\text { 50 GT }\end{array}$ & 1 \\
\hline KAPAL IKAN LUNAS 21 & 1 \\
\hline KAPAL IKAN LUNAS 10 & 1 \\
\hline KAPAL PENARIK 20 GT & 1 \\
\hline TOTAL & $\mathbf{2 1}$ \\
\hline
\end{tabular}

Pengrajin kapal kayu pada Kabupaten Batang walaupun memiliki pengetahuan tentang rancang bangun kapal tetapi belum memiliki teknik rancang bangun kapal secara modern ini dapat terlihat pada saat pembangunan kapal tidak dilengkapi gambar teknik mengenai lambung kapal maupun gambar teknik lainnya ini terlihat hampir disemua pengrajin di daerah Batang belum memiliki pengetahuan tentang gambar teknik kapal yang disebabkan juga karena tingkat pendidikan para pengrajin kapal kayu maupun pengetahuan pembangunan yang diperoleh secara turun temurun menyebabkan pengetahuan tersebut hanya berdasarkan pengalaman yang diturunkan secara langsung dimana pengalaman terdahulu pun belum memiliki pengetahuan tentang gambar 
teknik lambung kapal.

Armada kapal perikanan nasional, sampai dengan saat ini, masih didominasi oleh berbagai jenis perahu dan kapal penangkap ikan tradisional (disebut dengan "kapal ikan tradisional"). Umumnya, kapal ikan tradisional terbuat dari kayu dengan ukuran kurang dari 30 GT dan dibangun oleh galangan atau pengrajin kapal kayu tradisional, sehingga mempunyai corak yang spesifik untuk masing-masing daerah. Karena sifatnya tradisional, maka acuan dalam pelaksanaan pembangunannya tidak berdasarkan gambar rancang-bangun (design) dan spesifikasi teknis yang lengkap, melainkan berdasarkan pengalaman yang dimiliki secara turun-temurun dan mengikuti sistem tradisi masyarakat setempat[7]. Sehingga proses pembuatan kapal dapat dikatakan menggunakan metode tradisional dan kepercayaan mereka terhadap perkembangan teknologi sangatlah rendah. Hal ini menyebabkan perlunya sosialisasi mengenai teknologi perkapalan kepada pengrajin kapal di kabupaten Batang terutama dibidang rancang bangun(design) dan konstruksi kapal serta standar baku mengenai konstruksi kapal kayu yang sesuai dengan standar Biro Klasifikasi Indonesia (BKI) sehingga kapal akan memenuhi tingkat standar yang baku.Sehingga perlunya institusi pendidikan utamanya yang bergerak di bidang maritim untuk dapat membantu pengrajin memahami mengenai kurva hidrostatik dan konstruksi kapal kepada pengrajin tanpa menghilangkan bentuk lambung yang telah ada..

\subsection{Tujuan}

Berdasarkan identifikasi permasalahan terhadap pengrajin kapal kayu di wilayah Kabupaten Batang Jawa maka kegiatan ini akan mengambil bagian mengenai desain kapal dan konstruksi kapal kayu dengan program aplikasi Fishipro adapaun kegiatan meliputi sebagai berikut

1. Memberikan workshop mengenai program aplikasi Fishipro.

2. Memberikan pengetahuan mengenai aplikasi program desain kapal dengan software kapal yang ada.

3. Memberikan workshop mengenai konstruks kapal kayu.

\section{TINJAUAN PUSTAKA}

\subsection{Program Fishipro}

Fishipro merupakan program aplikasi yang dikembangkan oleh tim dari Jurusan Teknik Perkapalan Universitas Diponegoro dimana aplikasi program ini merupakan desain kapal kayu untuk tipe Batang dimana data utama didalam program aplikasi Fishipro meruapakan kapal-kapal yang dibangun digalangan kapal kayu di Kabupaten Batang.

Fishipro sendiri dikembangkan untuk memudahkan proses desain kapal kayu dimana desain akan diambil dari database yang ada pada program Fishipro sehingga setelah desainer melakukan inputan parameter dimensi kapal maka akan didapatkan desain kapal yang sesuai dengan parameter yang telah di masukan.

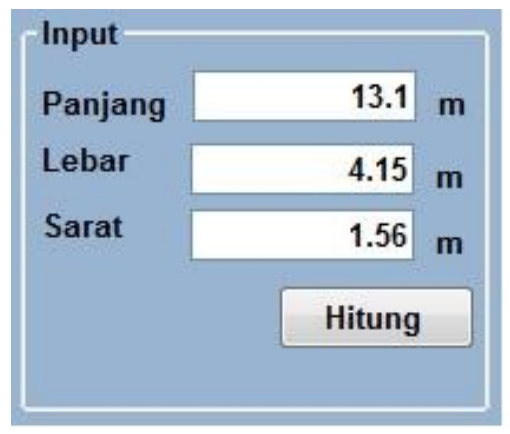

Gambar 2. Inputan untuk program Fishipro

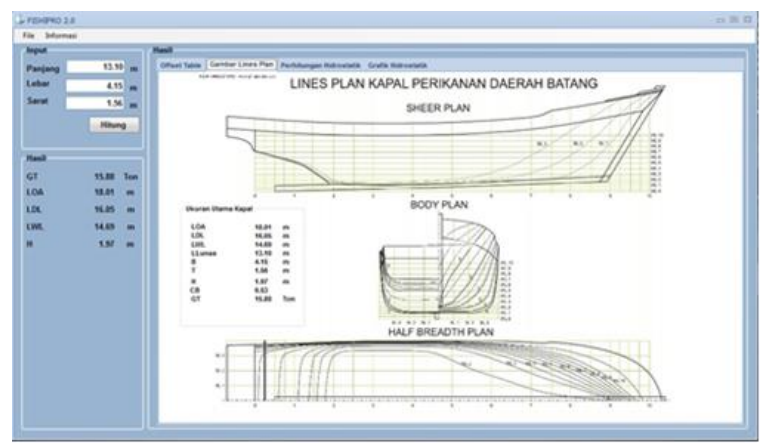

Gambar 3. GUI interface dari program Fishipro 


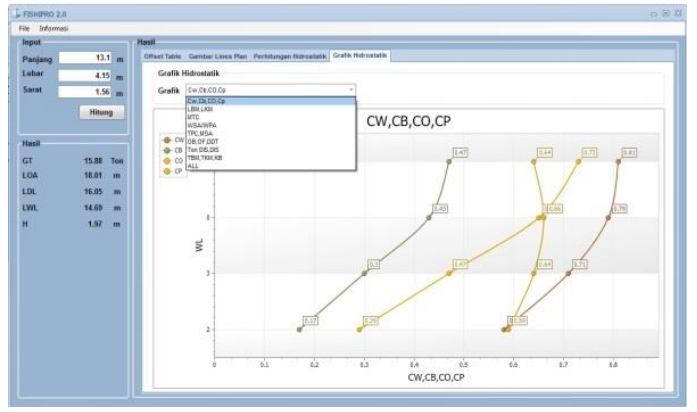

Gambar 3. Out put dari program Fishipro

Setelah input dari ukuran utama kapal maka langkah selanjutnya akan dicari bentuk lambung kapal yang sesuai ukuran utama kapal yang di inginkan dengan cara interpolasi yang terdapat pada database yang ada maka setelah dilakukan perhitungan dan telah memenuhi kriteria inputan maka hasil dari software tersebut adalah koordinat lambung kapal kayu yang sama seperti yang pengrajin bangun. Database yang digunakan oleh perancang software adalah kapal kayu yang pernah dibuat oleh pengrajin atau kapal kayu kabupaten Batang sehingga karakteristik kapal akan sama dengan yang dibuat oleh pengrajin kapal kayu. Output dari software dapat digunakan untuk penggambaran Rencana Garis kapal bangunan baru sehingga perlunya pemahaman dari perancang software ke pengrajin kapal kayu agar terjadi transfer ilmu kepada para pengrajin kapal kayu.

\subsection{Program Konstruksi Kapal Kayu}

Dalam kegiatan pengabdian ini untuk memberikan pengetahuan mengenai desain konstruksi kapal kayu maka akan digunakan aplikasi yang telah dikembangkan oleh jurusan Teknik Perkapalan dimana program tersebut Fishing Vessel construction yang dikembangkan oleh mahasiswa dan dosen Jurusan Perkapalan.

Program aplikasi ini merupakan aplikasi dari aturan BKI mengenai kapal kayu tahun 1996[3] karena minimnya akan sertifikasi kapal kayu maka peraturan ini tidak banyak berkembang dibandingkan kapal baja. Seperti halnya program Fishipro maka program ini memiliki database mengenai aturan dimensi profile kayu yang ada pada peraturan BKI 1996 sehingga dengan inputan parameter dimensi kapal akan didapatkan dimensi profile kayu yang akan digunakan dalam pembuatan kapal.

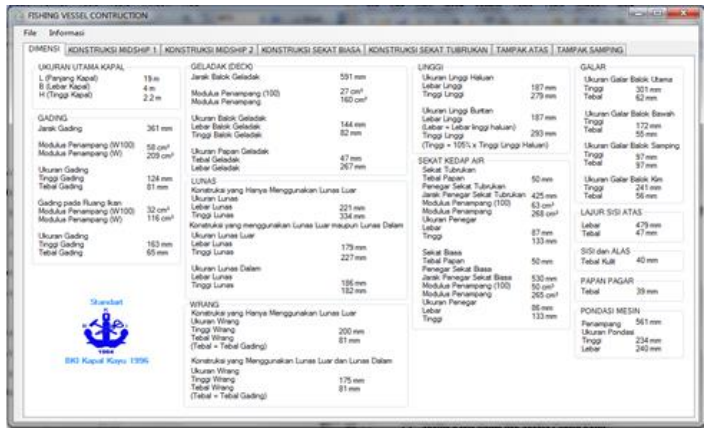

Gambar 4. Out put dari program konstruksi kapal kayu

Diharapkan dengan penggunaan program aplikasi ini memudahkan dalam kegiatan di lokasi galangan kapal kayu dimana sebagian besar pekerja adalah lulusan dari SMA. Untuk memudahkan dalam penggunaan program ini juga telah dibuatkan modul mengenai program Fishing Vessel Construction.

\section{METODOLOGI}

Kegiatan ini merupakan kegiatan pengabdian masyarakat yang didanai oleh Dikti pada tahun 2015 dimana penjabaran kegiatan akan dijabarkan pada Tabel 2. Dimana tim pengabdian merupakan lintas bidang dari 3 jurusan yang ada pada Fakultas Teknik Universitas Diponegoro.

Tabel 2. Kegiatan yang akan dilaksanakan oleh Tim pengabdian

\begin{tabular}{|l|ll|}
\hline No & \multicolumn{1}{|c|}{ Nama Kegiatan } \\
\hline 1. & a. & Pelatihan Software konstruksi kapal dan \\
& & Hidrostatik untuk kapal Batang \\
& b. & Pelatihan dan workshop mengenai \\
& & konstruksi kapal kayu \\
& c. & Pembuatan gambar hidrostatik untuk kapal \\
& & kayu. \\
\hline 2. & $\begin{array}{l}\text { Peningkatan kualitas pembangunan kapal } \\
\text { tradisional : }\end{array}$ \\
& a. & $\begin{array}{l}\text { Pelatihan pengenalan ilmu rancang bangun } \\
\text { kapal secara modern. } \\
\text { b. }\end{array}$ \\
& & $\begin{array}{l}\text { Pelatihan teknik menggambar bentuk } \\
\text { lambung kapal }\end{array}$ \\
\hline
\end{tabular}




\begin{tabular}{|l|ll|}
\hline & $\begin{array}{l}\text { c. } \\
\text { d. }\end{array}$ & $\begin{array}{l}\text { Pelatihan teknik konstruksi kapal kayu } \\
\text { hidrostatik kapal }\end{array}$ \\
\hline 3. & Konsultasi dan monitoring \\
\hline
\end{tabular}

\section{HASIL DAN PEMBAHASAN}

Kegiatan pengabdian yang telah dilaksanakan pada Kabupaten Batang telah dilaksanakan pada Juli 2015-Agustus 2015 dimana lokasi galangan kapal kayu terletak pada desa Karangasem Utara. Langkah dalam pengabdian adalah melakukan survey awal dan melakukan sosialisasi kepada pemilik galangan yaitu $H$. Nur Abadi selaku pemilik galangan CV. Abadi Group dan pekerja galangan sehingga tim pengabdian mampu membuat mencapai tujuan dari pengabdian di kabupaten Batang.

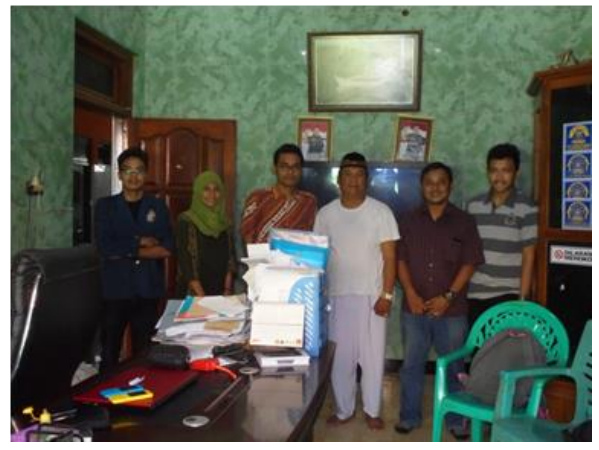

Gambar 5. Survey awal dengan pemilik galangan kapal

Berdasarkan pertemuan dengan pemilik galangan kapal kayu maka selanjutnya adalah melakukan konsolidasi tim yang dibantu mahasiswa untuk melakukan kegiatan pengabdian di lokasi galangan kapal kayu. Pembuatan modul untuk kegiatan dilokasi serta pembuatan poster maupun banner untuk kegiatan pengabdian.

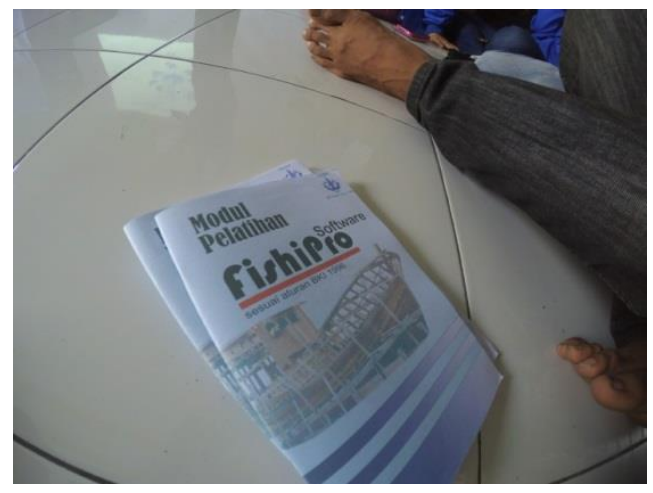

Gambar 6. Salah modul kegiatan pengabdian

Kegiatan pengabdian masyarakat ini telah berhasil dilaksanakan oleh tim bekerjsama dengan mahasiswa serta pekerja galangan namun diperlukan waktu yang lebih untuk mencapai hasil yang lebih baik lagi agar pemahaman mengenai program Fishipro maupun mengenai konstruksi kapal kayu akan lebih komperensif dan meningkatkan sumber daya manusia yang ada pada galangan kapal kayu di CV. Abadi Nur

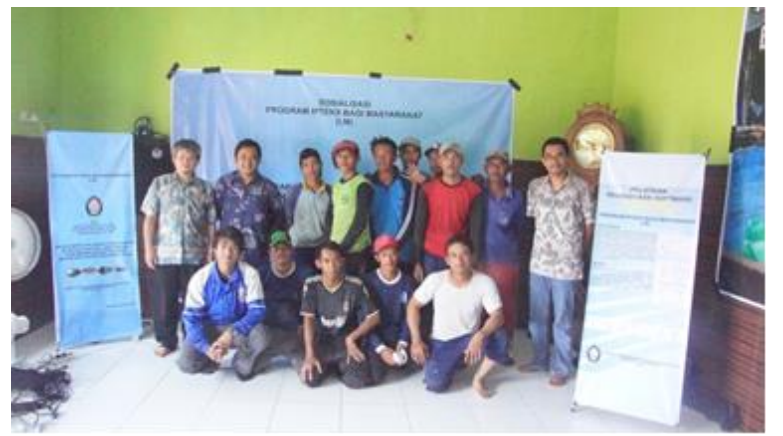

Gambar 7. Sesi foto dengan tim dosen dan pekerja galangan kapal kayu

\section{KESIMPULAN DAN SARAN}

\subsection{Kesimpulan.}

Berdasarkan hasil dari kegiatan pengabdian kepada masyarakat(IbM) di Karangasem Utara kabupaten Batang dapat disimpulkan sebagai berikut:

a) Pengabdian masyarakat telah sukses dilaksanakan dilokasi galangan kapal CV. Abadi Group dengan menggunakan software kapal seperti Delftship, Fishipro.

b) Meningkatnya pengetahuan pekerja mengenai proses desain kapal serta konstruksi kapal kayu dengan progam aplikasi praktis seperti Fishipro.

c) Meningkatnya pemahaman penggunaan program bidang perkapalan dalam proses produksi kapal.

\subsection{Saran}

Berdasarkan dari kegiatan pengabdian masyarakat ini beberapa saran yang dapat dilakukan di masa yang akan datang diantaranya :

1. Perlunya partisipasi pemerintah daerah untuk pendampingan pekerja mengenai pentingnya K3 dalam proses produksi.

2. Peran serta kesadaran akan penggunaan teknologi informasi dalam pemasaran kapal 
kayu sehingga memudahkan bagi pihak yang akan membeli kapal kayu.

3. Peningkatan sumberdaya manusia pada pekerja galangan kapal.

\section{UCAPAN TERIMA KASIH}

Penulis ingin mengucapkan terima kasih atas dibiayainya kegiatan pengabdian ini oleh Direktorat Riset dan Pengabdian Masyarakat Kementerian Riset, Teknologi dan Pendidikan Tinggi dengan Nomor : 012 / SP2H / PPM / DIT.LITABMAS / II / 2015

\section{DAFTAR PUSTAKA}

[1] Ardidja, Supardi. 2007. Kapal Penangkap Ikan. Sekolah Tinggi Perikanan. Jakarta

[2] Trimulyono, Andi dkk. 2013. Pemberdayaan Masyarakat Pesisir Di Kabupaten Batang Jawa Tengah Melalui Pengembangan Industri Galangan Kapal Tradisional. Laporan Akhir KKN-PPM, Semarang

[3] Biro Klasifikasi Indonesia, 1996. Buku Peraturan Klasifikasi dan Konstruksi Kapal Kayu. BKI. Jakarta.

[4] Masrul, Melly, 2009. Pengukuran Kapal Perikanan. Balai Besar Pengembangan Penangkapan Ikan. Semarang

[5] Ngumar, H.S, 2004. Identifikasi Ukuran Kapal. Departemen Pendidikan Nasional, Direktorat Jendral Pendidikan Dasar dan Menengah, Direktorat Pendidikan Menengah Kejuruan. Jakarta

[6] Sub Direktorat Rancang Bangun Dan Konstruksi Kapal Perikanan, 2004, Profil Kapal Perikanan. Departemen KelautanDan Perikanan Direktorat Jenderal Perikanan Tangkap. Jakarta

[7] Rahardjo ,Oktavian. 2008. Pengaruh Bentuk Buritan Dan Penempatan Sistem Penggerak Terhadap Kinerja Kapal Ikan Tradisional. Tesis Magister FTK, ITS

[8] Wahyono, Agung. 2011. Kapal Perikanan (Membengun Kapal Kayu). Balai Besar Pengembangan Penangkapan Ikan. Semarang. 